\title{
A close look at the role of regulatory fit in consumers' responses to unethical firms
}

\author{
Kwansik Mun \\ School of Journalism and Mass Communication, University of Wisconsin \\ Madison, Wisconsin USA \\ Ilgi Shin \\ College of Fine Art \& Design, Incheon Catholic University \\ Incheon, South Korea
}

\begin{abstract}
Our knowledge is not enough to clearly explain how consumers respond to unethical firms, thereby forming attitudes toward unethical firms' brand and buying their products. In this sense, we conduct a one-way experimental design to test regulatory focus theory when it comes to attitudes toward unethical firms' brand and the purchase intention. Our findings reveal that promotion-oriented participants were more negative toward Mitsubishi, which violates achievement (e.g. fuel efficiency), than prevention-oriented participants. More importantly, promotion-oriented people were less likely to buy Mitsubishi automobiles than prevention-oriented people. In contrast, prevention-oriented consumers are negative toward Volkswagen which violates protection (e.g. carbon dioxide emission reduction).
\end{abstract}

Keywords - Corporate Crisis, Brand Attitudes, Ethical Management, Purchase Intention, Regulatory Focus Orientation

SUGGESTED CITATION: Mun. K., \& Shin. I. (2018). A close look the role of regulatory fit in consumers' responses to unethical firms. Proceedings of the International Crisis and Risk Communication Conference (pp. 46-49). Orlando, FL, USA. Nicholson School of Communication. https://doi.org/10.30658/icrcc.2018.13

\section{INTRODUCTION}

Business ethic has been considered as a significant factor to explain consumers' brand attitude and intention to purchase products in strategic communication fields. Indeed, much attention to manage corporate reputation including business ethic has been paid among communication scholars and professionals. In this regard, most of them have explored how to strategically communicate with consumers when business scandals are uncovered. For example, research on crisis communication provided empirical evidence which messages are appropriate to get consumers' forgiveness depends on the types of crisis. However, most research on crisis communication has paid little attention to how consumers respond to the unethical management of corporation.

Accordingly, it is necessary to better understand how consumers think about unethical issues because such sense gives strategic communication professionals and scholars solutions to recovery the relationship between firms and consumers. For this, we borrowed the theoretical framework from regulatory focus, which was proposed by Higgins and his colleagues, given that regulatory focus theory has enabled us to interpret human behavior depends on their characteristics: promotion and prevention-orientations [1].

\section{LITERAURE REVIEW}

Regulatory focus theory assumes that either promotion-orientation or prevention-orientation differently serves human beings' behavior as the role of motivation. Promotion-orientation is related to nurturance and achievement while prevention-orientation is associated with safety and responsibility [1]. In this sense, much attention to regulatory fit has been drawn among psychological scholars in order to explain how people evaluate their decision; that is, violating regulatory fit has been regarded as a bad decision. For instance, two different regulatory orientations differentiate the meaning of being a good physician. For promotion-oriented people, a good physician provides patients with a new prescription under controlling risks. In contrast, prevention-oriented people believe that a good physician offers patients medication in a conservative way [2].

In line with this premise, regulatory fit has been applied to the exploration of consumer psychology in terms of people's consuming products [3], and perceiving consumer ethics [4]. However, it is questionable how regulatory fit accounts for consumers' response to unethical firms. For instance, Avnet [5] conducted the experimental design to 
provide evidence how regulatory fit differentiates people's response to the different type of companies (i.e., a for-profit vs. a not-for-profit company) at the time of a corporate's crisis. The findings showed that there are the differences of participants' perception based on the conditions of regulatory fit. People in the regulatory fit condition thought that a forprofit company is responsible for the accident and had a negative attitude toward the company. But, under non-fit condition, participants believed that a not-for-profit company is responsible for the accident and their attitude toward the company was less favorable. Indeed, the analysis showed the interaction between the types of companies and regulatory fit at the time of crisis. In this sense, this study raises one question of how consumers react to the different types of unethical managements of companies. To answer theoretically this question, this study calls for scholarly attention to Mitsubishi and Volkswagen scandals. Mitsubishi automobile company falsified documents relevant to a fuel-efficiency [6]. And Volkswagen automobile company manipulated systems in order to prove that their products are qualified for the rules of the Environmental Protection Agency in the United States [7]. Given the theoretical framework addressed above, therefore, this study postulates below.

H1a: Promotion-oriented people are more negative toward Mitsubishi brand than promotion-oriented people.

H1b: Promotion -oriented people's purchase intention of Mitsubishi is lower than promotion-oriented people's.

H2a: Prevention-oriented people are more negative toward Volkswagen brand than prevention-oriented people.

H2b: Prevention-oriented people's purchase intention of Volkswagen is lower than prevention-oriented people's.

\section{METHODS}

\section{PARTICIPANTS}

In order to make participants involve in the experiments, additional credits were offered to them. The current study collected data from 175 undergraduate students, who were taking psychology classes during a summer semester, in South Korea. The average of their age is $21.31(S D=1.609$, $\operatorname{Min}=20$, Max $=27) .35 .4 \%$ of the participants $(n=62)$ were males and $62.9 \%(n=110)$ were females.

\section{PROCEDURE AND EXPERIMENTAL DESIGN}

A one-way experimental design (promotion vs. prevention orientation) was employed to take a look at how regulatory focus orientations have a critical impact on attitude toward unethical firms' brand and people's purchase intention of unethical firms. First of all, participants were randomly exposed to news coverages (in Korean), which were designed to manipulate their regulatory focus orientation. The first story is to introduce internship programs and demonstrate a college student's successful experience to get through this program. The other one is about an environmental problem that serious air pollution happens in South Korea. In particular, the news coverage reports that particulate matter, which is mainly generated by vehicle emissions, causes serious disease.

After participants read each news story, they answered 18 questions to estimate regulatory focus. Second, participants were asked to answer their prior knowledge and issue interesting about Mitsubishi or Volkswagen scandal. This step is to clearly exclude the impact of participants' pre-existing knowledge toward two companies when we analyze the effect of regulatory focus on both attitude toward brand and purchase intention. Third, either Mitsubishi or Volkswagen scandal news (in Korean) was randomly exposed to participants. After reading each news coverage, participants were required to answer the questions measuring their attitude toward brand and purchase intention.

\section{MEASURES}

Attitude toward the target brand, participants' brand attitude toward Mitsubishi or Volkswagen was measured based on four seven-point semantic differential scales (good/bad, like/dislike, worthy/worthless, and distinguished/undistinguished) For Mitsubishi, the average score of brand attitude is 5.042 ( $S D=1.038$, Cronbach's alpha $=.820)$. For Volkswagen, the average score of brand attitude is $4.49(S D=.961$, Cronbach's alpha $=.833)$.

Intention to purchase the target brand, participants' purchase intention was estimated based one seven-point semantic differential scale: I am willing to purchase Mitsubishi (or Volkswagen) if I have a chance to buy (1) I am unwilling to purchase Mitsubishi (or Volkswagen) even if I have a chance to buy (7). For a Mitsubishi group, the average score of purchase intention is $5.85(S D=1.451)$. For a Volkswagen group, the average score is $5.01(S D=1.393)$.

\section{RESULTS}

\section{Manipulation check}

Employing the work of Lockwood, Jordan and Kunda [8], the current study measured participants' regulatory focus orientations based on a seven-point scale ranging from strongly disagree (1) to strongly agree (7). Overall, Cronbach's alpha on promotion-relevant items was .808. Cronbach's alpha on prevention-relevant responses was .693. In order to check whether participants' regulatory focus orientation was manipulated, this study calculated the difference between job-relevant news readers and environment-relevant news readers. For this, first, this study estimated the difference between an average score of promotion-orientation responses and an average score of prevention-orientation responses. 
Second, t-test was employed to check if there is the difference between different news story groups. According to the analysis, people who read a job-relevant news were promotion-oriented $(M=1.014, S D=1.005, \mathrm{n}=87)$ while people who read an environment-relevant news were prevention-oriented $(M=.543, S D=.854, \mathrm{n}=88)(\mathrm{t}(179)=3.741, \mathrm{p}<.001)$.

\section{ANALYTICAL ANALYSIS}

This study employs univariate analysis and controls covariates: issue interest, issue knowledge, age, perceived environmental situation, and perceived economic situation. For a Mitsubishi group, age ( $M=21.27, S D=1.645)$, issue interest $(M=1.55, S D=1.048)$, issue knowledge $(M=1.38, S D=1.019)$, perceived economic situation $(M=2.62, S D=$ 1.074), and perceived environmental situation $(M=2.43, S D=1.195)$ were measured.

\section{HYPOTHESES TEST}

For a Volkswagen group, age $(M=21.34, S D=1.582)$, issue interest $(M=2.67, S D=1.737)$, issue knowledge $(M=$ $2.47, S D=1.835)$, perceived economic situation $(M=2.66, S D=1.016)$, and perceived environmental situation $(M=$ 2.41, $S D=1.024$ ) were assessed.

H1a was significantly supported $(\mathrm{F}(1,76)=11.417, p<.001)$; namely, promotion-oriented people $(M=5.375)$ are more negative toward Mitsubishi than prevention-oriented people $(M=4.600)$. And, H1b was supported statistically and marginally $(\mathrm{F}(1,76)=3.718, p=.058)$; promotion-oriented people $(\mathrm{M}=6.07)$ were less likely to purchase Mitsubishi products than prevention-oriented people $(M=5.59)$.

In terms of attitude toward Volkswagen, H2a was significantly supported $(\mathrm{F}(1,80)=12.672, p<.001)$; preventionoriented people were more negative $(M=4.846)$ than promotion-oriented people $(M=4.092)$. However, H2b was not supported $(\mathrm{F}(1,80)=1.427, p=$ n.s. $)$.

\section{CONCLUSION AND DISCUSSION}

Our findings are theoretically supported. This study aims to broaden the theoretical development of regulatory focus explaining consumer behavior in unethical firms. Even though it has been taken granted that the unethical management of corporates influence consumers' behavior psychologically, there was no evidence of how consumers evaluate and react to such unethical management. In this regard, our findings reveal that perceived the unethical management of corporates is depending on consumers' regulatory focus orientations; indeed, promotion-oriented consumers have a negative attitude toward Mitsubishi which violates achievement (e.g. fuel efficiency). In contrast, prevention-oriented consumers are negative toward Volkswagen which violates protection (e.g. carbon dioxide emission reduction). More importantly, promotion-oriented people who have a negative attitude toward Mitsubishi are less likely to buy Mitsubishi automobiles.

However, there exist some limitations to generalize these findings. First, this study did not figure out the role of brand attachment in moderating the impact of negative publicity. For instance, Ahluwalia, Burnkrant, and Unnava [9] found that low-commitment consumers rather than high-commitment consumers were willing to change their attitude toward the target brand when they were exposed to negative information regarding the target brand. Second, this study did not investigate the role of corporate social responsibility (CSR). According to Klein and Dawar [10], consumers' perceived CSR made people to think that external and uncontrolled factors determine a product harm crisis when consumers positively perceived prior CSR. However, their CSR perception caused people to evaluate that internal and controlled factors are related to a product harm crisis when consumers negatively recognized prior CSR. Along with this theoretical assumption, it is questionable how participants' brand commitment and CSR perception of Mitsubishi (or Volkswagen) influences the relationship between perceived unethical management of Mitsubishi (or Volkswagen) and attitudes toward Mitsubishi brand (or Volkswagen).

Nevertheless, this study has theoretical and practical implications. First of all, the types of news coverage potentially differentiate readers' regulatory focus orientation although this study did not theoretically insist how news coverages impact regulatory focus orientations. In order to manipulate participants' regulatory focus orientations, this study simply employed two types of news coverage stories based on job and environmental issues. But, it is plausible that people who read a certain kind of news coverage could be either promotion-oriented or prevention-oriented because a situation incites an individual's orientation [2]. More importantly, this allows us to carefully look at how the types of crisis situations of corporates could be differently interpreted; namely, people who read an environmental news are more likely to negatively evaluate the brand when they read a following news that a corporate violates protection. In contrast, people who read an economic issue are more likely to negatively perceive the brand when they read a following news that a corporate violates achievement. Given the findings, it is necessary for crisis communication practitioners to think how their target consumers react to their company depends on where their crisis is dealt in newspapers. Therefore, regulatory focus orientations are manifest in the crisis management context [5]. 


\section{Author Biography}

Kwansik Mun (kmun@wisc.edu) is a Ph.D candidate at the University of Wisconsin-Madison, USA.

Ilgi Shin (shinilgi@iccu.ac.kr) earned a Ph.D. from Hanyang University and is an assistant professor in Incheon Catholic University, South Korea.

\section{REFERENCES}

[1] Higgins, E. T. (1997). Beyond pleasure and pain. American Psychologist, 52(12), 1280-1300. http://doi.org/10.1037/0003066X.52.12.1280

[2] Camacho, C. J., Higgins, E. T., \& Luger, L. (2003). Moral value transfer from regulatory fit: What feels right is right and what feels wrong is wrong. Journal of personality and social psychology, 84(3), 498-510. http://doi.org/10.1037/00223514.84.3.498

[3] Avnet, T., \& Higgins, E. T. (2006). How regulatory fit affects value in consumer choices and opinions. Journal of Marketing Research, 43(1), 1-10. https://doi.org/10.1509/jmkr.43.1.1

[4] De Bock, T., \& Van Kenhove, P. (2010). Consumer ethics: The role of self-regulatory focus. Journal of Business Ethics, 97(2), 241-255. https://doi.org/10.1007/s10551-010-0507-0

[5] Avnet, T. (2013). It's not us, it's them: Consumers' reactions to a company in a PR crisis and the value of being honest. Yeshiva University.

[6] Soble, J. (2016, April 21). Mitsubishi discloses it cheated on fuel test, New York Times, p. B1.

[7] Ewing, J. (2015, December 11). Volkswagen cites 'Chain of Errors' in emissions cheating, New York Times, p. B1.

[8] Lockwood, P., Jordan, C. H., \& Kunda, Z. (2002). Motivation by positive or negative role models: Regulatory focus determines who will best inspire us. Journal of personality and social psychology, 83(4), 854-864. http://dx.doi.org/10.1037/0022-3514.83.4.854

[9] Ahluwalia, R., Burnkrant, R. E., \& Unnava, H. R. (2000). Consumer response to negative publicity: The moderating role of commitment. Journal of Marketing Research, 37(2), 203-214. https://doi.org/10.1509/jmkr.37.2.203.18734

[10] Klein, J., \& Dawar, N. (2004). Corporate social responsibility and consumers' attributions and brand evaluations in a product-harm crisis. International Journal of Research in Marketing, 21(3), 203-217. https://doi.org/10.1016/j.ijresmar.2003.12.003 